\title{
Determination of Optimal Self-Drive Tourism Route Using the Orienteering Problem Method
}

Article $\cdot$ April 2013

DOI: $10.1063 / 1.4801296$

CITATIONS

3

3 authors, including:

\section{Zakiah Hashim}

Universiti Utara Malaysia

7 PUBLICATIONS 3 CITATIONS

SEE PROFILE
READS

282

Wan Rosmanira Ismail

National University of Malaysia

74 PUBLICATIONS 130 CITATIONS

SEE PROFILE

Some of the authors of this publication are also working on these related projects: 


\section{AIP Conference Proceedings}

Determination of optimal self-drive tourism route using the orienteering problem method

Zakiah Hashim, Wan Rosmanira Ismail, and Norfaieqah Ahmad

Citation: AIP Conf. Proc. 1522, 1420 (2013); doi: 10.1063/1.4801296

View online: http://dx.doi.org/10.1063/1.4801296

View Table of Contents: http://proceedings.aip.org/dbt/dbt.jsp?KEY=APCPCS\&Volume=1522\&lssue=1

Published by the American Institute of Physics.

\section{Additional information on AIP Conf. Proc.}

Journal Homepage: http://proceedings.aip.org/

Journal Information: http://proceedings.aip.org/about/about_the_proceedings

Top downloads: http://proceedings.aip.org/dbt/most_downloaded.jsp?KEY=APCPCS

Information for Authors: http://proceedings.aip.org/authors/information_for_authors

Article-level metrics now available 


\title{
Determination of Optimal Self-Drive Tourism Route Using the Orienteering Problem Method
}

\author{
Zakiah Hashim $^{\mathrm{a}}$, Wan Rosmanira Ismail ${ }^{\mathrm{b}}$ and Norfaieqah $\mathrm{Ahmad}^{\mathrm{b}}$ \\ ${ }^{a}$ Quantitative Sciences Department, College of Art and Sciences, \\ Universiti Utara Malaysia, 06010 UUM, Sintok, \\ Kedah DA, Malaysia \\ ${ }^{b}$ School of Mathematical Sciences, Faculty of Science and Technology, \\ Universiti Kebangsaan Malaysia, 43600 UKM Bangi, \\ Selangor DE, Malaysia
}

\begin{abstract}
This paper was conducted to determine the optimal travel routes for self-drive tourism based on the allocation of time and expense by maximizing the amount of attraction scores assigned to each city involved. Self-drive tourism represents a type of tourism where tourists hire or travel by their own vehicle. It only involves a tourist destination which can be linked with a network of roads. Normally, the traveling salesman problem (TSP) and multiple traveling salesman problems (MTSP) method were used in the minimization problem such as determination the shortest time or distance traveled. This paper involved an alternative approach for maximization method which is maximize the attraction scores and tested on tourism data for ten cities in Kedah. A set of priority scores are used to set the attraction score at each city. The classical approach of the orienteering problem was used to determine the optimal travel route. This approach is extended to the team orienteering problem and the two methods were compared. These two models have been solved by using LINGO12.0 software. The results indicate that the model involving the team orienteering problem provides a more appropriate solution compared to the orienteering problem model.
\end{abstract}

Keywords: optimal travel route, self-drive tourism, orienteering problem, team orienteering problem PACS: 02.60.Pn Numerical optimization

\section{INTRODUCTION}

Tourism is one of the important industries for the country because it is a major contributor to the country's growth. According to World Tourism Organization (WTO), the terms of tourism refers to "Activities of an individual traveling to a place outside their original environment and living there for not more than one consecutive year for leisure, business and other purposes." The main purpose of travel is to visit tourist attractions around the location.

According to the UN World Tourism Organization [1], a total of 982 million international tourists traveled the world in the year 2011, an increase of 4.6\% compared to 2010. Tourism industry directly involved over 5\% of Gross Domestic Product (GDP), 30\% of the world export of services, and one out of every twelve jobs (UNWTO), [1]. Thus, tourism industry development is very important so that more jobs can be created, economic growth and national development can grow more rapidly. In Malaysia, the number of tourist arrivals was recorded at 24.7 million in 2011 and generated revenue of RM58.3 billion in the same year (Tourism Malaysia, 2011) [2]. Various government efforts to promote tourism in Malaysia conducted as campaigning 'Global Leaders for Tourism Campaign' organized by UNWTO combination and the World Travel \& Tourism Council (WTTC) in 2011. The campaign called on the leaders to acknowledge tourism's role in providing sustainable growth and balanced and give priority to the higher national policy to maximize its potential (UNWTO) [1].

As an ongoing effort to improve services for tourists, a tourism route model that is more efficient and dynamic must be created to help travelers plan their holidays. Plan travel routes could be developed through self-drive tour mode in which this self-drive tourists traveling to tourist attractions by driving their own vehicles [3]. Therefore, the tourist guides do not have to be used because more tourists are free to choose their route itself based on the available information, time and cost. Normally, tourists will choose the best route that connects a destination to the next as if looking for the route that has the shortest distance. A study by Wen [4] interpreted the shortest path as the minimum total distance to be traveled from one node to another node. Best route selection is important for self-drive tourists

\footnotetext{
Proceedings of the 20th National Symposium on Mathematical Sciences

AIP Conf. Proc. 1522, 1420-1430 (2013); doi: 10.1063/1.4801296

(C) 2013 AIP Publishing LLC 978-0-7354-1150-0/\$30.00
} 
because it will affect the amount of travel costs, time to travel and also the number of places can be visited. If the self-drive tourists make the mistakes in choosing a route to the destination, they will face the problem of rising costs and lack of time travel. According to Taplin [5], for most holiday makers traveling by car, the pursuit of satisfaction and enjoyment is limited by the length of time available and by travel distance.

A system of travel routes for a self-drive tour mode more efficient and competitive should be created as an effort to attract more tourists to visit Malaysia. Therefore, the study needs to be done to ensure effectiveness in implementing this mode of self-drive tour. This study uses actual tourism data for the Kedah state. Kedah was selected as a case study because it is one of the states in Malaysia which has many attractions such as the rich legacy of architecture, history and culture and the beauty of nature that could draw tourists to come here. This paper involves the actual road routes data length that connects an attractive tourist destination to another tourist destination in Kedah. Because this study involved only land and road links, the selection mode of vehicles used by tourists only ground vehicles such as cars, vans and others.

In this paper, we tried to develop self-drive tourism routing optimal model using orienteering problem. Actual data path length of a road linking the city to other cities in Kedah was used for this study. Cities involved in this study are Alor Setar, Jitra, Bukit Kayu Hitam, Kuala Nerang, Yan, Gurun, Sungai Petani, Sik, Baling and Kulim. Tourism data for each city that is tourist attractions can be visited by tourists around the ten cities were used in this study. The tourist attractions were selected based on recommendations derived from the Ministry of Tourism Malaysia website [6].

The specialty of this study lies in the accumulation of attractiveness scores in each city as the objective function of the method of orienteering problem. Team orienteering problem, is an extension of the orienteering problem in which there are some entities that will collect the attraction scores. Although the selection of this travel route looks simple and can be solved manually, but a model of a more systematic tourist routes should be established. Through modes of self-drive tour, tourists can plan their routes wisely and maximize scores attractions at each city visited based on the cost of travel and the time available. Score attraction is originally set based on tourist preference option on the attribute values of tourist locations they want to visit. When the attraction score is maximized, indirectly tourist satisfaction and interest in tourism activities can be achieved until the maximum possible level.

The paper is organized as follows. The next section is devoted to the orienteering problem (OP) and team orienteering problem (TOP) background. In section 3, we discuss the problem definition and section 4 was discussed about model development. Section 5 shows the results and discussions with section 6 giving the conclusion.

\section{ORIENTEERING PROBLEM (OP) AND TEAM ORIENTEERING PROBLEM (TOP) BACKGROUND}

As early year 1984, Tsiligirides [7] introduced orienteering sport that is a combination of cross-country running and navigation through the woods with a map and compass. Competitors start at regular time intervals and aims to find some kind of "control points" are placed in the forest where the location marked on the competitor's map. There are two types of orienteering, the first is orienteering event in which the competitors have to visit each of the control points in the order given and the winner will be able to achieve this in minimum time. The second type of orienteering is score orienteering event, where competitors do not have to visit all the controls. Each control has a certain score and competitors aim to maximize the total score within the time limit prescribed.

Vansteenwegen et al. [8] stated that the problem can be seen as a combination of orienteering between knapsack problem and the traveling salesman problem (TSP). In the study, he and his colleagues have focused on the whole of the orienteering problem and discuss extensions and variants of the problem and solution strategies and applications. According to them, the application of the orienteering tour problem requires a solution that is very fast and effective. This problem is expected to play an important role in the future development of the tourist planning problem.

Orienteering problem (OP) also known as selective traveling salesman problem by Laporte and Martello [9], and the problem of multiple collection problem by Butt and Cavalier [10]. Then the problem is extended to the team orienteering problem (TOP) where there are several entities which aims to raise scores available at each control point. This entity will visit different nodes and the score collected by each entity are aggregated. Each entity cannot pass through the same node, and not all of the nodes will be visited because of a time limit set.

In the study of Chao et al. [11], according to sports version, $m$ member in the group has a specific time and set goals. Their goal is to determine the route from the starting point to the end point through a subset of locations to maximize the total score. However, each member shall be through a subset of the same location. They present a fast and effective heuristic with over 353 test problems involving between 21 and 102 points. 
Vansteenwegen et al. [12] introduced a tourist expert system known as the City Trip Planner allows planning the trip for five cities in Belgium. This website emphasizes application of interest and then adjusts constraints tourist travel information on tourist location database to predict the individual interests of each tourist. The proposed solution approach is based on the Greedy Randomized Adaptive Search Procedure (GRASP) on team orienteering problem with time windows.

There are a variety of other applications such as ant colony optimization approaches by Ke et al. [13] also use the TOP method for solution of their problems. According to Ke et al. [13], most studies carried out focusing on heuristics and meta-heuristics such as tabu search, guided local search and others. However, the research problem can be resolved only with the limited size of the study in a reasonable amount of time. A meta-heuristic approach the connection path to solve TOP was introduced by Souffriau et al. [14] to test abnormalities in a quick and slow route using JAVA 1.6 encoding.

Tang and Miller-Hooks [15] use tabu search heuristic approach to solve the TOP. According to them, TOP is a variant of the vehicle routing problem in which a set of tour vehicles constructed so that the total collection remuneration received of visits to a subset of customers is maximized. Trip distance of each vehicle is limited by the pre-specified limit. The results of calculation experiments showed that the proposed technique produces high quality solutions that consistently outperform the other heuristics for TOP issued. Meanwhile, Zhu et al. [16] also propose a heuristic method based on the idea of local search. Their method was also used to team orienteering problem as a special case for tour planning problem. Numerical results indicate that their method produces a very good approximation solution with little computation effort compared with existing methods.

\section{PROBLEM DEFINITION}

In this paper, we present a study on a real road network that connected ten cities in Kedah (refer Figure 1). The tourist attractions in ten cities were selected based on recommendations derived from the Ministry of Tourism Malaysia website [6]. In addition, because the scope of our study focused on self-drive tour, so the tourist attractions in the Langkawi Island is not included in this study. Table 1 shows the ten cities and number of tourist attractions for each city that have been selected as a tour destination in this study.

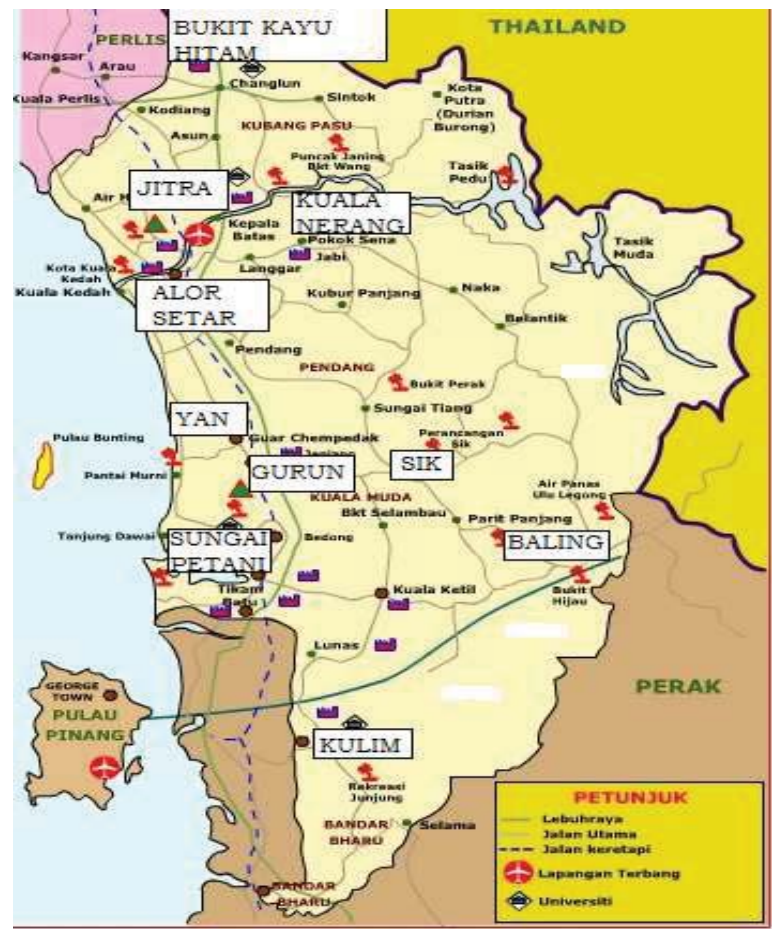

FIGURE 1. Map of Kedah State 
TABLE (1). Cities and number of tourist attractions

\begin{tabular}{lcc}
\hline City & Abbreviation & Number of Tourist Attractions \\
\hline Alor Setar & AS & 17 \\
Jitra & J & 6 \\
Bukit Kayu Hitam & BKH & 2 \\
Kuala Nerang & KN & 3 \\
Yan & Y & 5 \\
Gurun & G & 2 \\
Sungai Petani & SP & 10 \\
Sik & S & 3 \\
Baling & B & 8 \\
Kulim & K & 4 \\
\hline
\end{tabular}

This study involved a total of ten cities in Kedah which is shows in Table 1. Tourist attractions that can be accessed through a self-drive tour mode around these cities are also identified. Tourist attractions connected by roads alone will be selected for the purpose of this study. Tourists' arrival in Kedah will be based in Alor Setar, the capital of Kedah state. This can be achieved via several modes of transportation. For travelers flying, travelers will arrive in Sultan Abdul Halim Airport and for those who ride the express bus will arrive in Shahab Perdana Bus Terminal Alor Setar. As a result, Alor Setar is selected as the start and end destinations for the tour. Every tourist attractions in the surrounding towns involved are categorized according to their attributes. Category attribute is based on the major attractions featured on the website of Kedah Tourism Official Website 2011 [17]. Table 2 shows the list of attributes selected categories to classify each tourist attractions involved and Table 3 shows the total tourist attractions it each city according to the attribute value.

TABLE (2). List of attribute categories and priority score

\begin{tabular}{lcc}
\hline List of Attribute Categories & Abbreviation & Priority Score \\
\hline Beach Resort & B & 8 -very important \\
Meals & M & 2 \\
Handicrafts & C & 1 - very not important \\
Heritage and Architecture & A & 5 \\
Historical Site & H & 6 \\
Natural Beauty & N & 7 \\
Shopping Areas & S & 4 \\
Sports and Recreational Activities & R & 3 \\
\hline
\end{tabular}

TABLE (3). Total tourist attractions in each city according to the attribute value

\begin{tabular}{|c|c|c|c|c|c|c|c|c|c|c|}
\hline \multirow[b]{2}{*}{ Attribute } & \multicolumn{10}{|c|}{ City } \\
\hline & AS & $\mathbf{J}$ & BKH & KN & $\mathbf{Y}$ & G & SP & $\mathbf{S}$ & B & $\mathbf{K}$ \\
\hline B & - & - & - & - & 2 & - & 3 & - & - & - \\
\hline M & 3 & 1 & - & - & - & - & 2 & - & 1 & - \\
\hline $\mathrm{C}$ & 3 & - & 1 & - & - & - & 1 & - & 1 & - \\
\hline A & 12 & - & - & - & - & - & 1 & - & - & - \\
\hline H & 7 & 1 & - & - & - & - & 1 & - & - & - \\
\hline $\mathbf{N}$ & - & 1 & - & 3 & 5 & 2 & 1 & 3 & 7 & 3 \\
\hline $\mathbf{S}$ & 2 & 1 & - & - & - & - & 2 & - & 1 & - \\
\hline $\mathbf{R}$ & 1 & 4 & 2 & 3 & 3 & 2 & 5 & 2 & 6 & 4 \\
\hline
\end{tabular}

Choice preference scores may vary per tourist because every tourist has different interests and hobbies. Hence, a tourist site to be visited depends on the priorities set scores of tourists. Preference score was then multiplied by the total number of locations in each city tour by an attribute value as shown in Table 3 and the results are shown in Table 4. Score was assigned for each city named attraction scores. However, for nod 11 which is an end point in Alor Setar, we put 0 score for this node because this is only dummy point so that routes back to Alor Setar.

TABLE(4). Attractiveness score for each node

\begin{tabular}{lcccccccccc}
\hline $\begin{array}{l}\text { Node 1 } \\
\text { AS }\end{array}$ & $\begin{array}{c}\text { Node 2 } \\
\text { J }\end{array}$ & $\begin{array}{c}\text { Node 3 } \\
\text { BKH }\end{array}$ & $\begin{array}{c}\text { Node 4 } \\
\text { KN }\end{array}$ & $\begin{array}{c}\text { Node 5 } \\
\text { Y }\end{array}$ & $\begin{array}{c}\text { Node 6 } \\
\text { G }\end{array}$ & $\begin{array}{c}\text { Node 7 } \\
\text { SP }\end{array}$ & $\begin{array}{c}\text { Node 8 } \\
\text { S }\end{array}$ & $\begin{array}{c}\text { Node 9 } \\
\text { B }\end{array}$ & $\begin{array}{c}\text { Node 10 } \\
\text { K }\end{array}$ & $\begin{array}{c}\text { Node 11 } \\
\text { AS }\end{array}$ \\
\hline 119 & 31 & 8 & 30 & 60 & 20 & 70 & 27 & 74 & 33 & 0 \\
\hline
\end{tabular}




\section{MODEL DEVELOPMENT}

\section{Model Development Using Orienteering Problem (OP)}

This study employs a method of orienteering problem (OP) where a set of $\mathrm{N}$ nodes $i$ is given, each has $s_{i}$ score. The starting point (node 1) and the end point (node $\mathrm{N}$ ) is set. Time to travel from node $i$ to $\mathrm{j}\left(\mathrm{t}_{\mathrm{ij}}\right.$ ) is identified for all nodes. Not all nodes can be reached in view of the time available is limited to the provision of $T_{\max }$ given time. OP goal is to set the path to the limited number of nodes visited by $T_{\max }$ to maximize the amount of accumulation scores. Each node can be visited only once. OP can be formulated as an integer problem.

The decision variables are:

$\mathrm{x}_{i j}=1$ if a visit to node $i$ is followed by a visit to node $j$ - 0 otherwise;

$\mathrm{u}_{i}=$ position of node $i$ in the route

$$
\operatorname{Max} \sum_{i=2}^{N-1} \sum_{j=2}^{N} s_{i} x_{i j}
$$

Subject to:

$$
\begin{aligned}
& \sum_{j=2}^{N} x_{i j}=\sum_{i=1}^{N-1} x_{i N}=1 \\
& \sum_{i=1}^{N-1} x_{i k}=\sum_{j=2}^{N} x_{k j} \leq 1 ; \forall k=2, \ldots, N-1 \\
& \sum_{i=1}^{N-1} \sum_{j=2}^{N} t_{i j} x_{i j} \leq T_{\max } \\
& 2 \leq u_{i} \leq N ; \forall i=2, \ldots, N \\
& u_{i}-u_{j}+1 \leq(N-1)\left(1-x_{i j}\right) ; \forall i, j=2, \ldots, N \\
& x_{i j} \in\{0,1\} ; \forall i, j=1, \ldots, N
\end{aligned}
$$

Objective function (1) is to maximize total collected score. Constraints (2) ensure that the path starts at node 1 and ends at node N. Constraints (3) ensure the connectivity of the path and guarantee that each node is visited at most once. Constraints (4) ensure the limited time budget. Constraints (5) and (6) will be necessary to prevent subtours. Orienteering problem formulation is based on the study by Vansteenwegen et al. [8].

\section{Model Al}

Model A1 involves a set time limit of 12 hours a day to travel from 8 am to $8 \mathrm{pm}$. This time limit includes time traveling from city $i$ to city $j$ and time to visit the tourist sites around the city. Table 5 shows the data traveling from city $i$ to city $j$ obtained from Google Maps.

TABLE (5). Travel time in minutes from the city $i$ to city $j$

\begin{tabular}{lccccccccccc}
\hline $\mathbf{i} \backslash \mathbf{j}$ & $\mathbf{A S}$ & $\mathbf{J}$ & $\mathbf{B K H}$ & $\mathbf{K N}$ & $\mathbf{Y}$ & $\mathbf{G}$ & $\mathbf{S P}$ & $\mathbf{S}$ & $\mathbf{B}$ & $\mathbf{K}$ & $\mathbf{A S}$ \\
\hline $\mathbf{A S}$ & - & 26 & 49 & 49 & 57 & 51 & 47 & 83 & 106 & 128 & - \\
$\mathbf{J}$ & 26 & - & 26 & 42 & 74 & 42 & 55 & 73 & 96 & 105 & 26 \\
$\mathbf{B K H}$ & 49 & 26 & - & 56 & 85 & 58 & 71 & 90 & 112 & 126 & 49 \\
$\mathbf{K N}$ & 49 & 42 & 56 & - & 95 & 75 & 88 & 74 & 117 & 105 & 49 \\
$\mathbf{Y}$ & 57 & 74 & 85 & 95 & - & 31 & 56 & 62 & 85 & 108 & 57 \\
$\mathbf{G}$ & 51 & 42 & 58 & 75 & 31 & - & 31 & 32 & 55 & 81 & 51 \\
$\mathbf{S P}$ & 47 & 55 & 71 & 88 & 56 & 31 & - & 50 & 58 & 58 & 47 \\
$\mathbf{S}$ & 83 & 73 & 90 & 74 & 62 & 32 & 50 & - & 39 & 75 & 83 \\
$\mathbf{B}$ & 106 & 96 & 112 & 117 & 85 & 55 & 58 & 39 & - & 58 & 106 \\
$\mathbf{K}$ & 128 & 105 & 126 & 118 & 108 & 81 & 58 & 75 & 58 & - & 128 \\
$\mathbf{A S}$ & - & 26 & 49 & 49 & 57 & 51 & 47 & 83 & 106 & 128 & - \\
\hline
\end{tabular}


Only 8 hours allocated for a day trip. So, half of the trip time is added to the travel time from city $i$ to city $k$ and half is added to the travel time from city $j$ to city $k$. It is referred to the study by Vansteenwegen et al. [8]. Travel period set for this study was 3 days. This period was quite short because it suits the method of orienteering problem which is trying to determine the route with the limited time. So, the value $T_{\max }=12$ hours $\times 3$ days $=36$ hours is used for this model, which is equal to 2160 minutes.

Formulation of constraints (4) changed to:

$$
\sum_{i=1}^{N-1} \sum_{j=2}^{N}\left(4+t_{i j}\right) x_{i j} \leq T_{\max }
$$

The objective function (1) also changed so that the score for travel starting point included in the solution model and is formulated as:

$$
\operatorname{Max} \sum_{i=2}^{N-1} \sum_{j=2}^{N} s_{i} x_{i j}+s_{1}
$$

\section{Model A2}

Model A2 involves cost limit allocated for tourism activities. RON95 petrol was chosen because the cheaper price of RM1.90 per liter. Estimated per liter of petrol can be used for $10 \mathrm{~km}$ journey. So, every kilometer distance is multiplied by RM0.19 for petrol consumption costs. Cost of fuel consumption for the journey from city $i$ to city $j$ are illustrated in Table 6.

TABLE (6). Cost of petrol (RM) from the city $i$ to city $j$

\begin{tabular}{lccccccccccc}
\hline $\mathbf{i} \backslash \mathbf{j}$ & $\mathbf{A S}$ & $\mathbf{J}$ & $\mathbf{B K H}$ & $\mathbf{K N}$ & $\mathbf{Y}$ & $\mathbf{G}$ & $\mathbf{S P}$ & $\mathbf{S}$ & $\mathbf{B}$ & $\mathbf{K}$ & $\mathbf{A S}$ \\
\hline $\mathbf{A S}$ & - & 3.80 & 8.46 & 7.14 & 7.11 & 7.60 & 11.19 & 13.95 & 18.92 & 19.19 & - \\
$\mathbf{J}$ & 3.80 & - & 5.13 & 5.21 & 12.05 & 11.31 & 15.03 & 17.65 & 22.61 & 22.80 & 3.80 \\
$\mathbf{B K H}$ & 8.46 & 5.13 & - & 8.13 & 16.49 & 15.62 & 19.38 & 22.04 & 26.98 & 26.98 & 8.46 \\
$\mathbf{K N}$ & 7.14 & 5.21 & 8.13 & - & 16.44 & 13.41 & 18.56 & 15.11 & 18.60 & 22.61 & 7.14 \\
$\mathbf{Y}$ & 7.11 & 12.05 & 16.49 & 16.44 & - & 2.91 & 6.92 & 9.44 & 13.95 & 14.44 & 7.11 \\
$\mathbf{G}$ & 7.60 & 11.31 & 15.62 & 13.41 & 2.91 & - & 4.24 & 6.33 & 11.31 & 11.97 & 7.60 \\
$\mathbf{S P}$ & 11.19 & 15.03 & 19.38 & 18.56 & 6.92 & 4.24 & - & 9.88 & 10.98 & 7.96 & 11.19 \\
$\mathbf{S}$ & 13.95 & 17.65 & 22.04 & 15.11 & 9.44 & 6.33 & 9.88 & - & 8.04 & 13.36 & 13.95 \\
$\mathbf{B}$ & 18.92 & 22.61 & 26.98 & 18.60 & 13.95 & 11.31 & 10.98 & 8.04 & - & 10.77 & 18.92 \\
$\mathbf{K}$ & 19.19 & 22.80 & 26.98 & 22.61 & 14.44 & 11.97 & 7.96 & 13.36 & 10.77 & - & 19.19 \\
$\mathbf{A S}$ & - & 3.80 & 8.46 & 7.14 & 7.11 & 7.60 & 11.19 & 13.95 & 18.92 & 19.19 & - \\
\hline
\end{tabular}

Car rental costs are also involved in this model. On average, the cost of a car rental is RM100 for a day. So, for the 3 days tour, tourists need to pay RM 300 for car rental. Total budget expenditure suitable for travel mode is RM400.

Formulation of constraints (4) changed to:

$$
\sum_{i=1}^{N-1} \sum_{j=2}^{N} c_{i j} x_{i j} \leq C_{\max }
$$

where $c_{i j}=$ cost of fuel consumption for the journey from city $i$ to city $j$, and $C_{\max }=$ limited spending budget. $C_{\max }$ value can be calculated by simple calculations, $C_{\max }=400-300=100$. The objective function for this model is same as in Model A1.

\section{Model A3}

Model A3 is a combination of the two previous models. This combination resulted when the constraints (8) of the model A1 and constraints (10) of the model A2 are included in the model A3. This model used the same data as in the previous model. This model can be formulated as follows: 
$\operatorname{Max} \sum_{i=2}^{N-1} \sum_{j=2}^{N} s_{i} x_{i j}+s_{1}$

Subject to:

$$
\begin{aligned}
& \sum_{j=2}^{N} x_{i j}=\sum_{i=1}^{N-1} x_{i N}=1 \\
& \sum_{i=1}^{N-1} x_{i k}=\sum_{j=2}^{N} x_{k j} \leq 1 ; \forall k=2, \ldots, N-1 \\
& \sum_{i=1}^{N-1} \sum_{j=2}^{N}\left(4+t_{i j}\right) x_{i j} \leq T_{\max } \\
& \sum_{i=1}^{N-1} \sum_{j=2}^{N} c_{i j} x_{i j} \leq C_{\max } \\
& 2 \leq u_{i} \leq N ; \forall i=2, \ldots, N \\
& u_{i}-u_{j}+1 \leq(N-1)\left(1-x_{i j}\right) ; \forall i, j=2, \ldots, N \\
& x_{i j} \in\{0,1\} ; \forall i, j=1, \ldots, N
\end{aligned}
$$

\section{Model Development Using Team Orienteering Problem (TOP)}

The team orienteering problem (TOP) is an OP where the goal is to determine D routes, each limited by $T_{\max }$ that maximizes the total collected score. The TOP can be formulated as an integer problem with these decision variables:

$x_{i j d}=1$ if, in route $d$, a visit to node $i$ is followed by a visit to node $j$ - 0 otherwise;

$y_{i d}=1$ if node $i$ is visited in route $d-0$ otherwise;

$u_{i d}=$ the position of node $i$ in route $d$.

$$
\operatorname{Max} \sum_{d=1}^{D} \sum_{i=2}^{N-1} s_{i} y_{i d}
$$

Subject to:

$$
\begin{aligned}
& \sum_{d=1}^{D} \sum_{j=2}^{N} x_{1 j d}=\sum_{d=1}^{D} \sum_{i=1}^{N-1} x_{i N d}=D \\
& \sum_{d=1}^{D} y_{k d} \leq 1 ; \forall k=2, \ldots, N-1 \\
& \sum_{i=1}^{N-1} x_{i k d}=\sum_{j=2}^{N} x_{k j d}=y_{k d} ; \forall k=2, \ldots, N-1 ; \forall d=1, \ldots, D \\
& \sum_{i=1}^{N-1} \sum_{j=2}^{N} t_{i j} x_{i j d} \leq T_{\max } ; \forall d=1, \ldots, D \\
& 2 \leq u_{i d} \leq N ; \forall i=2, \ldots, N ; \forall d=1, \ldots, D \\
& u_{i d}-u_{j d}+1 \leq(N-1)\left(1-x_{i j d}\right) ; \forall i, j=2, \ldots, N ; \forall d=1, \ldots, D
\end{aligned}
$$

The objective function (19) is to maximize the total collected score. Constraints (20) guarantee that each route starts in node 1 and ends in node N. Constraints (21) ensure that every node is visited at most once. Constraints (22) guarantee the connectivity of each route. Constraints (23) ensure the limited time budget for each route. Constraints (24) and (25) are necessary to prevent subtours. The TOP formulation is based on the study by Vansteenwegen et al. [8]. 


\section{Model B1}

Model B1 involves time limits set out in the rules of group orienteering problem. This model aims to determine the route for each day $d$ during the holiday $D$ and maximize the total collected score on every day in every city they visited. Every day trip will start from Alor Setar and will go back there again at the end of the daily tours.

Travel period set for this study is a 3-day $(\mathrm{D}=3)$. The travel time budget is 12 hours a day, which is from 8 am to $8 \mathrm{pm}$ during the holiday period provided. This is because many of the places visit not operate at night and are suitable as a rest time at the night before traveling the next day. So appropriate value of $T_{\max }$ is 12 hours.

Data from Table 5 of the time taken in traveling from city $i$ to city $j$ is also used in this model. Visited time allocation for 8 hours was set, producing different formulations to the constraints (23). This formulation referred to the study by Tang and Miller-Hooks [15].

$$
\sum_{i=1}^{N-1} \sum_{j=2}^{N} t_{i j} x_{i j d}+\sum_{i=2}^{N-1} l_{i} y_{i d} \leq T_{\max } ; \forall d=1, \ldots, D
$$

where $l_{i}$ represent time spent in the city $i$. The objective function for this model was also changed so that the score for the starting point is also taken into account in the model solution.

$$
\operatorname{Max} \sum_{d=1}^{D} \sum_{i=2}^{N-1} s_{i} y_{i d}+s_{1}
$$

\section{Model B2}

Model B2 involving cost allocation for tourism activities. Limited expenses used for this study because it suits the team orienteering problem methodological approaches that try to determine the route based on the limited resource expenditure. RON95 petrol was chosen because the cheaper price of RM1.90 per liter. Data of fuel consumption cost for the journey from city $i$ to city $j$ in Table 6 were used in this model.

The model also takes into account the estimated cost of the car rental of RM100 for a day. The total cost of a car rental for 3 days is RM 300. Accommodation costs are also taken into account by choosing the residence with the cheapest rental rates. There are some accommodations in Alor Setar which offers low rental rates starting price RM25. So, travelers need to produce as much as RM75 for 3 days accommodation in Alor Setar. Thus, the appropriate total expenditure for travel modes was estimated at RM475. So, the value $C_{\max }=(475-300-75) \div 3=$ $100 / 3$.

Formulation of constraints (23) of changed to:

$$
\sum_{i=1}^{N-1} \sum_{j=2}^{N} c_{i j} x_{i j d} \leq C_{\max } ; \forall d=1, \ldots, D
$$

where $c_{i j}=$ cost of fuel consumption for the journey from city $i$ to city $j$, and $C_{\max }=$ limited spending budget. The objective function for this model is same as in Model B1.

\section{Model B3}

Model B3 is a combination of the two previous models. This combination resulted when the constraints (26) of the model B1 and constraints (28) of the model B2 are included in the model B3. This model used the same data as in the previous model. This model can be formulated as follows:

$$
\begin{aligned}
& \operatorname{Max} \sum_{d=1}^{D} \sum_{i=2}^{N-1} s_{i} y_{i d}+s_{1} \\
& \text { Subject to: } \\
& \sum_{d=1}^{D} \sum_{j=2}^{N} x_{1 j d}=\sum_{d=1}^{D} \sum_{i=1}^{N-1} x_{i N d}=D
\end{aligned}
$$




$$
\begin{aligned}
& \sum_{d=1}^{D} y_{k d} \leq 1 ; \forall k=2, \ldots, N-1 \\
& \sum_{i=1}^{N-1} x_{i k d}=\sum_{j=2}^{N} x_{k j d}=y_{k d} ; \forall k=2, \ldots, N-1 ; \forall d=1, \ldots, D \\
& \sum_{i=1}^{N-1} \sum_{j=2}^{N} t_{i j} x_{i j d}+\sum_{i=2}^{N-1} l_{i} y_{i d} \leq T_{\max } ; \forall d=1, \ldots, D \\
& \sum_{i=1}^{N-1} \sum_{j=2}^{N} c_{i j} x_{i j d} \leq C_{\max } ; \forall d=1, \ldots, D \\
& 2 \leq u_{i d} \leq N ; \forall i=2, \ldots, N ; \forall d=1, \ldots, D \\
& u_{i d}-u_{j d}+1 \leq(N-1)\left(1-x_{i j d}\right) ; \forall i, j=2, \ldots, N ; \forall d=1, \ldots, D
\end{aligned}
$$

\section{RESULTS AND DISCUSSION}

To obtain results for the OP and TOP models, LINGO software version 12.0 was used. LINGO is a comprehensive computer software and effective way to solve the problem of modeling linear or non linear with the faster, easier and effectively [18]. In addition, LINGO is also a mathematical modeling language that allows us to express the optimization problem in a form similar to standard mathematical notation.

Model A1 wants to determine the optimal route of tourists with its main objective to maximize the attractiveness score of each city visited. Based on LINGO solution, the maximum attraction score obtained was 417 and the route is as follows:

$$
\text { Alor Setar } \rightarrow \text { Kuala Nerang } \rightarrow \text { Yan } \rightarrow \text { Sungai Petani } \rightarrow \text { Kulim } \rightarrow \text { Baling } \rightarrow \text { Jitra } \rightarrow \text { Alor Setar }
$$

No one can be specified accommodation during the tour. However, according to Table 7 can be recommended that travelers rent accommodation in the Yan on the first day, the second day of Kulim and in Alor Setar on the third day after visiting the tourist attractions around the cities.

TABLE (7). Traveling time (hour) solution from model A1

\begin{tabular}{lcc}
\hline Travel Route & $\mathbf{4}+\mathbf{t}_{\mathrm{ii}}$ & Total Time Using \\
\hline $\mathrm{AS} \rightarrow \mathrm{KN}$ & $4+0.82$ & 4.82 \\
$\mathrm{KN} \rightarrow \mathrm{Y}$ & $4+1.58$ & 10.4 \\
$\mathrm{Y} \rightarrow \mathrm{SP}$ & $4+0.93$ & 15.33 \\
$\mathrm{SP} \rightarrow \mathrm{K}$ & $4+0.97$ & 20.3 \\
$\mathrm{~K} \rightarrow \mathrm{B}$ & $4+0.97$ & 25.27 \\
$\mathrm{~B} \rightarrow \mathrm{J}$ & $4+1.6$ & 30.87 \\
$\mathrm{~J} \rightarrow \mathrm{AS}$ & $4+0.43$ & 35.3 \\
\hline
\end{tabular}

Model A2 also want to maximize the attractiveness score of each city with limited expenditure cost and without specifying the provision of travel time. The result solution of LINGO 12.0 obtained that maximum attraction of the score is 472 with the total fuel consumptions of RM 84.19. Travel route during the tour are as follows:

$$
\begin{aligned}
& \text { Alor Setar } \rightarrow \text { Bukit Kayu Hitam } \rightarrow \text { Jitra } \rightarrow \text { Kuala Nerang } \rightarrow \text { Baling } \rightarrow \text { Sik } \rightarrow \text { Kulim } \rightarrow \text { Sungai Petani } \rightarrow \\
& \text { Yan } \rightarrow \text { Gurun } \rightarrow \text { Alor Setar }
\end{aligned}
$$

Model A3 contains constraints such as those found in two previous models that prescribe the use of time and travel expenses during the period. The results of LINGO solution find collected attractions scores of 417. Total travel time usage for this model is 34.78 hours at a fuel cost of RM 71.73. Summary of tourist routes derived from the outcome of this model is shown below:

$$
\text { Alor Setar } \rightarrow \text { Sungai Petani } \rightarrow \text { Baling } \rightarrow \text { Kulim } \rightarrow \text { Yan } \rightarrow \text { Kuala Nerang } \rightarrow \text { Jitra } \rightarrow \text { Alor Setar }
$$


Result from LINGO show that the maximum attraction scores for Mode B1 is of 323. Referring to the solution below, the tourists will stay in Alor Setar during the holiday. Summary of daily travel throughout the tour are as follows:

Day 1: Alor Setar $\rightarrow$ Baling $\rightarrow$ Alor Setar with the total travel time usage of 11.53 hours.

Day 2: Alor Setar $\rightarrow$ Sungai Petani $\rightarrow$ Alor Setar with the total travel time usage of 9.57 hours.

Day 3: Alor Setar $\rightarrow$ Yan $\rightarrow$ Alor Setar with the total travel time usage of 9.9 hours.

Result from LINGO show that the maximum attraction scores for Model B2 is of 365. Summary of daily travel throughout the tour are as follows:

Day 1: Alor Setar $\rightarrow$ Kuala Nerang $\rightarrow$ Bukit Kayu Hitam $\rightarrow$ Jitra $\rightarrow$ Alor Setar with the total fuel cost of RM 24.20.

Day 2: Alor Setar $\rightarrow$ Gurun $\rightarrow$ Sungai Petani $\rightarrow$ Alor Setar with the total fuel cost of RM 23.03.

Day 3: Alor Setar $\rightarrow$ Sik $\rightarrow$ Alor Setar with the total fuel cost of RM 27.90.

Model B3 contains constraints such as those found in two previous models that prescribe the use of time and travel expenses during the period. The results of LINGO solution find collected attractions scores of 280. Summary of daily travel throughout the tour are as follows:

Day 1: Alor Setar $\rightarrow$ Sungai Petani $\rightarrow$ Alor Setar with the total travel time usage of 9.57 hours and total fuel cost of RM 22.38.

Day 2: Alor Setar $\rightarrow$ Yan $\rightarrow$ Alor Setar with the total travel time usage of 9.9 hours and total fuel cost of RM14.22.

Day 3: Alor Setar $\rightarrow$ Jitra $\rightarrow$ Alor Setar with the total travel time usage of 8.52 hours and total fuel cost of RM 7.60.

TABLE (8). Summary of the result

\begin{tabular}{|c|c|}
\hline Orienteering Problem & Team Orienteering Problem \\
\hline Model A1: $Z=417$ & Model B1: $Z=323$ \\
\hline $\mathrm{AS} \rightarrow \mathrm{KN} \rightarrow \mathrm{Y} \rightarrow \mathrm{SP} \rightarrow \mathrm{K} \rightarrow$ & a. $\quad \mathrm{AS} \rightarrow \mathrm{B} \rightarrow \mathrm{AS}$ \\
\hline $\mathrm{B} \rightarrow \mathrm{J} \rightarrow \mathrm{AS}$ & b. $\quad \mathrm{AS} \rightarrow \mathrm{SP} \rightarrow \mathrm{AS}$ \\
\hline & c. $\quad \mathrm{AS} \rightarrow \mathrm{Y} \rightarrow \mathrm{AS}$ \\
\hline Travel time: 35.3 hours & Travel time: $11.53+9.57+9.9=31$ hours \\
\hline Model A2: $Z=472$ & Model B2: $Z=365$ \\
\hline $\mathrm{AS} \rightarrow \mathrm{BKH} \rightarrow \mathrm{J} \rightarrow \mathrm{KN} \rightarrow \mathrm{B} \rightarrow$ & a. $\mathrm{AS} \rightarrow \mathrm{KN} \rightarrow \mathrm{BKH} \rightarrow \mathrm{J} \rightarrow \mathrm{AS}$ \\
\hline $\mathrm{S} \rightarrow \mathrm{K} \rightarrow \mathrm{SP} \rightarrow \mathrm{Y} \rightarrow \mathrm{G} \rightarrow \mathrm{AS}$ & b. $\quad \mathrm{AS} \rightarrow \mathrm{G} \rightarrow \mathrm{SP} \rightarrow \mathrm{AS}$ \\
\hline & c. $\quad \mathrm{AS} \rightarrow \mathrm{S} \rightarrow \mathrm{AS}$ \\
\hline Fuel cost: RM 84.19 & Fuel cost: $24.20+23.03+27.90=$ RM 75.13 \\
\hline Model A3: Z = 417 & Model B3: $Z=280$ \\
\hline $\mathrm{AS} \rightarrow \mathrm{SP} \rightarrow \mathrm{B} \rightarrow \mathrm{K} \rightarrow \mathrm{Y} \rightarrow$ & a. $\quad \mathrm{AS} \rightarrow \mathrm{SP} \rightarrow \mathrm{AS}$ \\
\hline $\mathrm{KN} \rightarrow \mathrm{J} \rightarrow \mathrm{AS}$ & b. $\quad \mathrm{AS} \rightarrow \mathrm{Y} \rightarrow \mathrm{AS}$ \\
\hline & c. $\quad \mathrm{AS} \rightarrow \mathrm{J} \rightarrow \mathrm{AS}$ \\
\hline Travel time: 34.78 hours & Travel time: $9.57+9.9+8.87=28.34$ hours \\
\hline Fuel cost: RM 71.73 & Fuel cost: $22.38+14.22+7.60=\mathrm{RM} 44.20$ \\
\hline
\end{tabular}




\section{CONCLUSIONS}

Based on the findings in Table 8 , it was found that using the TOP model gives better results compared the model using the OP. This is because the TOP model provides an ideal solution when the set stays in one place, which is in Alor Setar. Thus, the collected attraction scores, total travel time and fuel cost consumption is lower than the OP model. The study was conducted by placing certain limits of time and cost to suit the needs of tourists who have time constraints and limited expenses for tourism activities. With a limited allocation of resources, tourist cannot visit all the tourist attractions there. So, tourists can choose to visit a particular tourist attraction if visiting that city.

Any weaknesses of this study need to be improved so that a better outcome can be obtained. One of the suggestions for improvement this model is to consider more carefully other relevant information such as the time and entrance cost to particular sightseeing tour and time set by a tour of the place. With this, the budget allocation and spending time set capable of satisfying the requirements of self-drive tourists.

\section{REFERENCES}

1. UN World Tourism Organization, "Collection of Tourism Expenditure Statistics", UNWTO Technical Manual No. 2, 2011.

2. Tourism Malaysia, Tourist arrivals and receipts to Malaysia, http://corporate.tourism.gov.my/ research.asp?page= facts_ figures (10 June 2012).

3. M. Olsen, "Keeping Track of the Self Drive Market" in Drive Tourism: Up the Wall and Around the Bend, by D. Carson et al., Melbourne: Common Ground Publishing, 2002.

4. L. Y. Wen, Journal of Network and Computer Applications 27, 151-162 (2004).

5. J. H. E. Taplin, and C. McGinley, Annals of Tourism Research 27(2), 451-467 (2000).

6. Ministry of Tourism Website. http://www.tourism.gov.my/destinations. (30 January 2012).

7. T. Tsiligirides, The Journal of the Operational Research Society 35(9), 797-809 (1984).

8. P. Vansteenwegen et al., European Journal of Operational Research 209, 1-10 (2011).

9. G. Laporte and S. Martello, Discrete Applied Mathematics 26, 193-207 (1990).

10. S.E. Butt and T.M. Cavalier, Computers \& Operations Research 21(1), 101-111 (1994).

11. I. M. Chao et al., European Journal of Operational Research 88, 464-474 (1996).

12. P. Vansteenwegen et al., Expert Systems with Applications 38, 6540-6546 (2011).

13. L. Ke, et al., Computers \& Industrial Engineering 54, 648-665 (2008).

14. W. Souffriau, et al., Computers \& Operations Research 37, 1853-1859 (2010).

15. H. Tang, and E. Miller-Hooks, Computers \& Operations Research 32(6), 1379-1407 (2005).

16. C. Zhu et al., Annals of Operations Research 192(1), 67-86 (2012).

17. Kedah Tourism Official Website 2011. http://www.tourism.gov.my/kedah/ (3 January 2012).

18. L. Schrage, Optimization Modelling with Lingo, USA: Lindo System Inc., 2006. 